\title{
Eski Malatya'dan Malatya'ya Mevsimlik Göç ile Başlayan Mekân Kurma Geleneğinin, Zorunlu Göç ile Kalıcı Yerleşime Dönüşmesi: Sivil mimari yerleşim özellikleri üzerine bir inceleme
}

\author{
* \\ Yelda Durgun Şahin ${ }^{1}$ \\ ORCID: 0000-0001-6708-9247
}

Öz

Sivil mimarlık örnekleri, değişen yaşam tarzıyla birlikte, nüfus artışı, çarpık kentleşme, zorunlu göç, kullanılmama vb. nedenler ile özgün niteliklerini günden güne yitirmektedirler. Tek tek kaybedilen bu yapılar ile geleneksel yerleşim dokusu zarar görerek yok olmaktadır. Bu nedenle yapı ile kent arasında köprü görevi üstlenen bu ara bağlantının incelenip, yerleşim özelliklerinin belirlenmesi ve kayıt altına alınması gerekmektedir. Bu bağlamda kentin şekillenmesinde etken olan, toplumun mekân kurma pratiğinin de yapı ve yakın çevresi açısından sorgulanması önem taşımaktadır.

1838'de II. Mahmut'un emriyle alınmış olan askeri güvenlik kararı doğrultusunda, Hafız Mehmet Paşa ordusunun, Eski Malatya' da yer alan evlere yerleştirilmiş olduğ u bilinmektedir. Bu çerçevede bu makale, alınan bu stratejik kararn bir sonucu olarak, yaşanan zorunlu göçe tanıklı eden Eski Malatya ve Malatya (yeni yerleşim alanı) sivil mimarlık örneklerini, arazi kullanımı, yerleşim düzeni, yapı-açık alan ilişkisi, yapı giriş ilişkisi yönlerinden ele almaktadır. Bu ilişkiler 11 adet Eski Malatya, 14 adet Malatya sivil mimari örneği örneklem alanı üzerinde değerlendirilmiştir. Eski Malatya ile Malatya evlerinin, yapı-açık alan kullanımındaki mekânsal karşılaştırmalar yapılmış ve değişimin anlamı değerlendirilmiştir. Böylece geçmiş yaşantılarımızı yansitan geleneksel evlerimiz ile kent ölçeği arasındaki bu ara bağlantının, yerleşim özellikleri belgelenmiştir. Sonuç olarak ortaya koyulan farklılık ve benzerlikteki anlamın, kent formunu etkileyerek, şekillendirmiş ve sinırlandırmış olduğu görülmüştür.

Anahtar Kelimeler: Sivil Mimari, Yerleşim Özellikleri, Geleneksel Kent Dokusu

${ }^{1}$ Dr. Öğr. Üyesi, Adana Alparslan Türkeş Bilim ve Teknoloji Üniversitesi,

E-mail: ydurgunsahin@atu.edu.tr

idealkent @ Kent Araştırmaları Dergisi (Journal of Urban Studies)

http://idealkentdergisi.com

Geliş Tarihi Received Date: 01.02.2020 Kabul Tarihi Accepted Date: 24.07.2020 


\title{
The tradition of establishing a space that started with seasonal migration from Old Malatya to Malatya turned into permanent settlement with forced migration: A review on the characteristics of civil architectural settlements
}

\author{
* \\ Yelda Durgun Şahin² \\ ORCID: 0000-0001-6708-9247
}

\begin{abstract}
Examples of civil architecture, along with the changing lifestyle, population growth, unplanned urbanization, forced migration, disuse etc. lose their original attributes day by day. With these buildings lost one by one, the traditional settlement texture is damaged and destroyed. For this reason, this interconnection, which acts as a bridge between the building and the city, needs to be examined, the characteristics of the settlement should be determined and recorded. In this context, it is important to question the space-building practice of the society, which is a factor in shaping the city, in terms of its structure and its immediate surroundings

As the Ottoman army settled in houses in Old Malatya in 1838, the people had to migrate to the settlement area of today's Malatya city. In this study, 11 Old Malatya and 14 Malatya (new residential areas) civil architecture examples are handled in terms of land use, settlement layout, building-open space relationship, building entrance relationship. Thus, it has been observed that this interconnection between our traditional houses, which reflect our past lives, and the urban scale, the difference and similarity revealed by documenting settlement features, has shaped and limited the urban form by influencing the urban form.
\end{abstract}

Keywords: Civil Architecture, Settlement Properties, Traditional Urban Texture

2 Asts. Prof, Adana Alparslan Türkeş Science and Technology University,

E-mail: ydurgunsahin@atu.edu.tr

idealkent @ Kent Araştırmaları Dergisi (Journal of Urban Studies)

http://idealkentdergisi.com

Geliş Tarihi Received Date: 01.02.2020 Kabul Tarihi Accepted Date: 24.07.2020 


\section{Giriş}

Kent, mekân ve zaman içindeki insan yerleşmesinin belli özellikler taşıyan bir özel durumu olarak anlatılabilir. Kent mekânında değişmeyi ve dönüşmeyi sürekli gündemde tutan nedenler vardır. Illhan Tekeli

(Tekeli, 2011a, s.16 ve Tekeli, 2011b, s.272)

Tekeli'nin anlatımıyla kentlerde olan bu özel durumun, değişen ve dönüşen nedenlerini, bir kent üzerinden öğrenmenin heyecanı hiç bitmez. Bu özel durum sayesinde kentler, kimliklerini kazanırlar. Çeşitli uygarlıkların birikimleri sonucu, mekânsal ve biçimsel anlamda zenginleşen kentler, o kente farklı bir kimlik kazandırmaktadır. Bu kimliğin korunmasıyla mimari ve kültürel süreklilik sağlanabilmektedir. Bu bağlamda tarihi süreç incelendiğinde koruma kavramının ilk olarak belirli kimliği olan yapılarla başlamış olduğunu, günümüzde ise bu kavram genişletilerek tek yapı ölçeğinden, kimliği olan sokak, mahalle, kentsel ölçeğe kadar genişlemiş olduğunu görmekteyiz (Ahunbay, 2017: 28). Geçmiş yaşantımıza ait değerli bilgiler taşıyan bu alanlar, yapılmış oldukları dönemin mimarisini, yerleşim özelliklerini ve sosyal yaşantısını günümüze kadar aktaran araçlar olmuşlardır

Panerai ve Castex (1970) çalışmalarında kent analizini yaparken öğelerin tipolojisi kavramına değinmişlerdir. Kentin iki temel ögesinin, binalar ve açık alanlar olduğunu belirterek, kentin bu öğelerinin türlerine ve biçimlerine göre sınıflandırıldığından bahsetmişlerdir (Panerai ve Castex, 1970, s.71). Bu nedenle çalışma, geleneksel evlerin bu ara ölçekteki bağlantısına, yerleşim özelliklerine göre sınıflandırılmasına odaklanmıştır. Bu anlamda Eski Malatya ve Malatya sivil mimarlık örneklerinden oluşan 25 geleneksel yapının, yerleşim özelliklerinin incelenmesi çalışmanın temel çıkış noktasını oluşturmuştur.

1838 'de II. Mahmut'un emriyle alınmış olan askeri güvenlik kararı doğrultusunda, Hafız Mehmet Paşa karargâhı ordusu, Eski Malatya'da yer alan evlere yerleştirilmiş ve savaşın uzaması ile ordunun uzun süre bu evleri kullanmış oldukları bilinmektedir. Eski Malatya' da yaşayan halk ise yazları yaylalık olarak kullandıkları Malatya'daki evlerine yerleşmişlerdir. Savaşın uzaması ve yıkıcı etkisi ile ordunun evlere vermiş olduğu büyük hasar neticesinde, halk tekrar Eski Malatya yerleşim alanına dönmemiştir. 
Bu doğrultuda, Eski Malatya dan Malatya'ya gerçekleşen mevsimlik göç ile zorunlu göçün bir birleşimi sonucu oluşan ve değişen sivil mimarlık örneklerinin incelenmesi ve yerleşim özelliklerinin belirlenerek gruplanması amaçlanmıştır. Çalışma içerisinde 14 adet Malatya sivil mimari örneği ve 11 adet Eski Malatya sivil mimari örneği yer almaktadır (Şekil 1.a ve 1.b). Bu örnekler yerleşim düzeni, yapı-açı alan ilişkisi, yapı-giriş ilişkisi açısından karşılaştırmalı olarak incelenmiştir.

Elde edilen tipolojik veriler ile Eski Malatya ve Malatya sivil mimari örneklerinin yerleşim özellikleri sistematik bir bakış açısı tanımlanmıştır. Farklı tipolojik verilerin, sosyo-ekonomik temellerdeki değişimden ve farklı yapım dönemlerindeki yasal düzenleme ilkelerindeki değişimlerden kaynaklanmış olduğu sonucuna varılmıştır. Çalışma gelecek nesillere aktarılması gereken tarihi belge özelliği taşıması açısından da önem taşımaktadır.

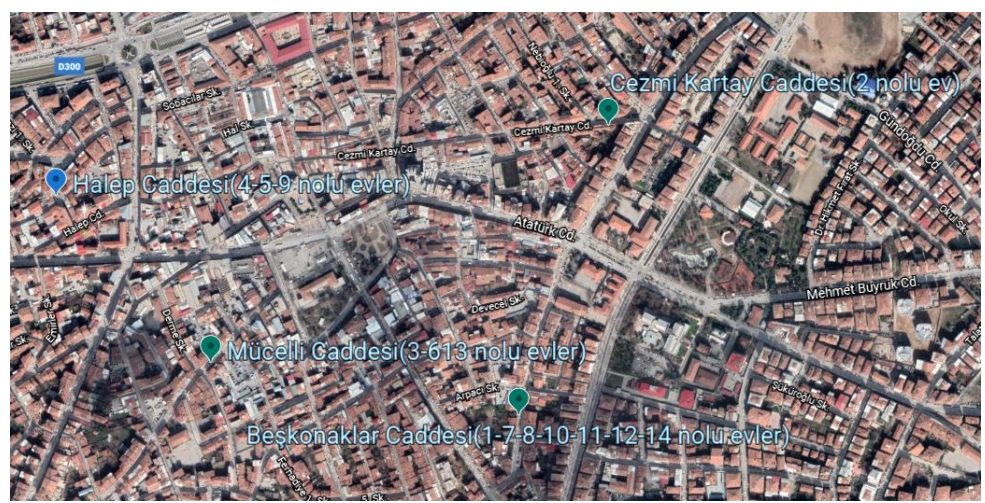

Şekil 1.a. 14 adet Malatya sivil mimari örneği alan çalışma alanı

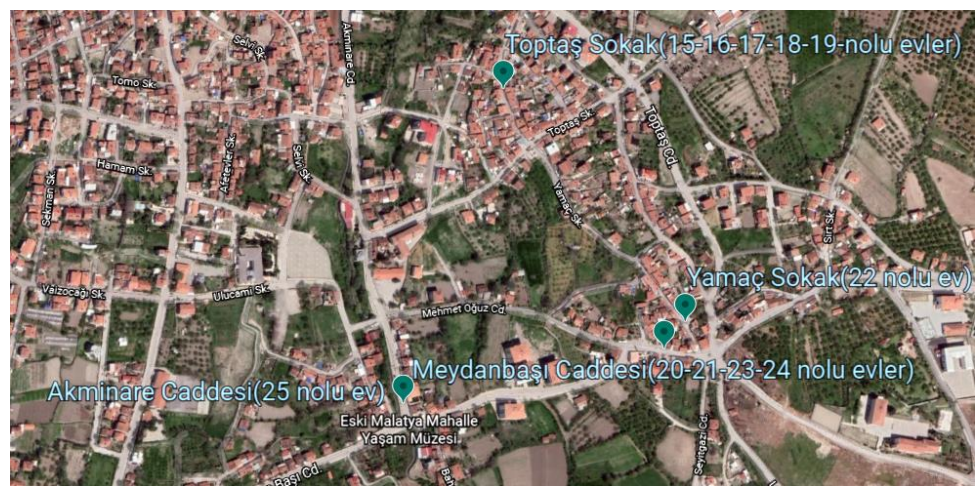

1.b. 11 adet Eski Malatya sivil mimari örneği alan çalışma alanı(Google Earth) 


\section{Yöntem}

Çalışmada inceleme alanlarına ait gözlem ve görsel kaynaklara dayalı olarak analiz ve sentez metodu kullanılmıştır. Konut yerleşim planları oluşturulurken rölöve belgeleme tekniği uygulanmıştır. Arazide yapılan fotoğraflama, tespit ve belgeleme neticesinde, belgeler dijital ortama autocad çizim programı ile aktarılmıştır. Dijital ortamdaki belgeler üzerinde karşılaştırma, yorumlama ve değerlendirme yöntemleri kullanılarak Eski Malatya ve Malatya evleri yerleşim doku ve plan analizleri doğrultusunda tipolojik veriler elde edilmiştir.

\section{Bulgular}

\section{Malatya'nın Fiziksel Özellikleri ve Kısa Tarihi Geçmişi}

Malatya ili, Doğu Anadolu coğrafi bölge sınırları içerisinde yer almaktadır. Kent, Orta Asya, Orta Doğu ve Mezopotamya'dan gelen ticarî yolların kesişmesi ve batıya bağlantı sağlayan bir konumda bulunması nedeniyle tarihte stratejik bir öneme sahip olmuştur. Malatya kenti iki defa yer değiştirme sonrasında, Beydağları' nın eteklerinde, ovalık alanda yeniden kurulmuş ve şekillenmiştir. Bu değişimin ilki Eski Malatya (Battalgazi) ilçesi Bahçebaşı kasabasında yer alan Arslantepe' den Eski Malatya (Battalgazi) ilçesine, ikincisi ise Eski Malatya' da günümüz yerleşim alanına Malatya (Aspuzu)' ya gerçekleşmiş olduğu bilinmektedir (Sağlam, Korkmaz, Bilgin, Demirbağ ve Memiş, 2013: 3-5). Yerleşimin yer değiştirmesi Şekil 2’ de kısaca özetlenmiştir.

\section{ARSLANTEPE}

(Bahçebaş1- En erken Kalkolitik döneme tarihlenen önemli bir Hitit yerleşimi)

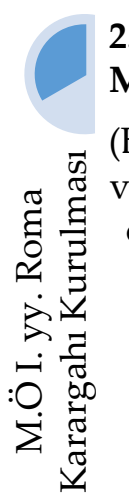

2.ESKI

\section{MALATYA}

(Battalgazi- Roma

ve Bizans dönemi

önemli şehirleri $=$ 光
3.MALATYA

(Aspuzu-

Günümüz

Malatya ili) arasinda)

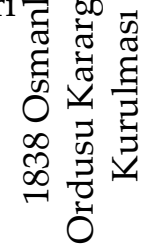

Şekil 2. Yerleşimin sırasıyla yer değiştirmesi 
Kente ait en eski yerleşimin ise Malatya'nın 7 km kuzeydoğusunda yer alan Arslantepe (Bahçebaşı) olarak bilinen alanda kurulduğu bilinmektedir. Bu yerleşimin en eski tarihlemesinin Kalkolitik döneme (M.Ö 5500-3000) kadar olduğu ve bölgenin 13.yüzyılda önemli bir Hitit kenti olduğu bilinmektedir. M.Ö 12. yüzyıl başına kadar Hitit imparatorluğu içinde bulunan şehir M.Ö 1114 yılında Asur krallığına bağlı devletin merkezi olmuş, M.Ö 800 yıllarına doğru Urartu devleti ve M.Ö 722'ye doğru yeniden Asurlular' in eline geçmiştir. Bu arada halkın ova içinde başka yerleşme noktalarına dağıldığı saptanmıştır (Sevgen, 1959: 240). Romalıların bölgeye gelip karargâhlarını Arslantepe'nin $4 \mathrm{~km}$. kuzeyinde kurmaları ile şehir yeni yerinde ortaya çımıştır ve şehrin ilk yer değiştirme hadisesi yaşanmıştır. Böylece kent, M.Ö I. yüzyılda bugünkü Eski Malatya'da yeniden kurulmuştur ve Romalılar tarafından Melitene adı verilmiştir (Ramsay, 1960: 35). Bizanslılar devrinde (M.S 395-659) de önemini koruyan kent, M.S 657-658 yıllarında Müslüman Araplar'ın eline geçmiştir. M.S 712 yılında ise iç karışıklıklar nedeni ile halkın şehri terk etmesinden dolayı Malatya'ya Ermeniler ve Arami dili konuşan köylüler yerleşmişlerdir. Kent M.S 1071 Malazgirt savaşı ile Türkler tarafından ele geçirilene kadar, Bizanslılar ve Müslüman Araplar arasında yönetsel anlamda el değiştirmiştir. İlerleyen dönemde ise Malatya, Danişmentliler' in merkezi olarak 1104 yılında tümüyle Selçuklular' in eline geçmiştir. Malatya mimarlık açısından en zengin dönemini Selçuklular zamanında yaşamıştır. Günümüze kadar ulaşan kervansaraylar, han ve hamamlar, camiler bu devirde yapılmıştır. 1392 Osmanlı yönetimine katılana kadar çeşitli Türk beyliklerinin egemenliğine girmiş ancak, Timur'un Anadolu'yu istilasında Memlüklüler'in eline geçerek asıl Osmanlı egemenliğine 1516'da girmiş olduğu bilinmektedir (Sevgen, 1959: 242). 1838'de II. Mahmut'un emriyle Hafız Mehmet Paşa ve karargâhının Eski Malatya'ya yerleşmesine kadar halk kışları Eski Malatya'da, yazları ise günümüz Malatya ili olarak bilinen, tarihdeki adıyla Aspuzu' da geçirmiş olduğu bilinmektedir. Ordunun Eski Malatya'daki kendi evlerine yerleşmesi ile Aspuzu' ya (bağ evlerine) taşınan halk, buraya bir şehir kurarak bir daha Eski Malatya'ya dönmemişlerdir (Turgut, 1999, s.10-19). Böylece Malatya, isim değiştirmeden ikinci kez yer değiştirerek bugünkü yerini almıştır.

\section{Malatya'nın Kentsel Gelişimi ve Türkiye'deki Planlama Anlayışı}

Yerel yönetim teşkilatı ile ilgili düzenlemelerin yapıldığı ilk resmi belge 17 Mayıs 1839 yılında hazırlanmıştır (Yerasimos, 1999: 1). "Illmühaber" adlı bu belgede kâgir binaların yapımı teşvik edilmiş, bu binaların arasında ahşap 
bina yapımı yasaklanmıştır (Tekeli 1999b, s.23-24). Osmanlı Devleti'nin ilk anayasası olan 1876 Kanun-i Esasi'nin illerin yönetimi ve düzenlenmesinin sağlandığı, 1877'de I. Meşrutiyet Meclisinden çıkartılan bir yasa ile belediyelerin kurulması gerekliliği vurgulanmıştır (Lewis, 1993, s.386; Kili ve Gözübüyük 2000, s.54). 1877 Belediye Kanunun üzerinden 5 yıl sonra (1882) Osmanlı Devleti'nin ilk imar kanunu kabul edilmiştir (Tekeli, 1985a, s.887).

Ülkede gerçekleşmiş olan bu planlama çalışmaları doğrultusunda, Malatya 1839-1845 yılları arasında Diyarbakır iline bağlı bir kaza iken, 1845-1874 yılları arasında sancak olarak görülmektedir. 1883 yılında Elazığ iline bağlanmıştır. 1918' e kadar Elazığ'a bağlı olduğu bilinmektedir(Göğebakan, 2003, s.473). Cumhuriyet' in ilan edilmesinden sonra 1924 Anayasast ile il olmuştur. Bu nedenle Malatya kazasında belediye binası yer almamıştır. İl olmasıyla birlikte bürokrasideki değişimler kente yansıyarak Malatya, kamusal alanlarda yeni bir kent planlama sürecine dâhil olmuştur. Henüz il olarak 96 yıllık bir geçmişe sahip olan kent, 1930’ larda ahşap bağ evleri ve kâgir yapılı evlerden oluşan bir kasaba görünümünde olduğu bilinmektedir. Sivil mimari, kaza, sancak ya da il olma sürecinde hep varlıklarını korumuşlardır. Ancak il olma sonrasında, ildeki bürokratların oturdukları konutlar farklılaşarak geleneksel Malatya evlerinin şekillenmesinde büyük rol almışlardır.

Malatya merkez Sinema caddesi üzerinde yer alan yan yana bitişik nizam inşa edilmiş beş adet konak da kentin maddi durumu yüksek kamu görevlilerinin oturmuş olduğu belirtilmiştir (Sağlam, Korkmaz, Bilgin, Demirbağ ve Memiş, 2013, s.49-51).

19. yy yapıları olan Geleneksel Malatya evlerinin bağ evleri içinde bulunan mevsimlik ahşap evlerden kalıcı kâgir yapılara dönüşmesini, Malatya'nın il olması ve ahşap yapı yapma yerine kâgir yapıların desteklenmesi gibi yasal düzenlemeler neticesinde olduğu düşünülmektedir.

1930'ların başında demiryolunun gelmesi, 1935'den sonra büyük bir dokuma fabrikasının kurulmasının planlanması, şehrin gelişerek büyüyeceğini, nüfusun ve yapılaşmanın hızla artacağını işaret etmektedir. Gerçekleşecek olan bu kentsel gelişim süreci, kentin planlanmasını zorunlu hale getirmiş olduğu görülür. 1935 Yılı Haziran ayında Ankara Bayındırlık direktörü Mimar Semih bey ve ekibi kent planlaması üzerine çalışmalar yapmış, büyük oranda bu planlama uygulama bulmuştur (Kızılkaya, 2018). Bu uygulama ile ikinci evre özelliği gösteren kent yoğunluğu artarak üçüncü evre yapılaşmasına geçmiştir. 


\section{Alan Çalışması/Eski Malatya ve Malatya Geleneksel Evlerinin Yerleşim Özellikleri}

Malatya halkının zorunlu göçe maruz bırakılmadan önceki yaşam alanı olan Eski Malatya ile yeni yerleşim alanlı olan Malatya geleneksel sivil mimari örnekleri örneklem alanı olarak seçilmiştir. Bu evlerin 11'i Eski Malatya'da, 14'ü Malatya'da olmak üzere toplam 25 geleneksel ev ve yakın çevresi çalışmanın kapsamını oluşturmuştur.

Geleneksel Eski Malatya ve Malatya evlerinin çoğu iki katlı olarak inşa edilmiştir. Evlerin bulunduğu sokaklar, Osmanlı döneminin kat-sokak genişliği ilkesi çerçevesinde, iki atın çektiği ve yan yana iki at arabası geçecek şekilde düzenlenmiş olduğu görülmüştür (Yaklaşık 580-600 cm). Evlerin büyük çoğunluğunun, iki kat yükseklikte olduğu dikkate alındığında, yaklaşık 6 metre yükseklik ile yol genişliğinin aynılığı dikkat çekmektedir. Tablo 1'de çalışma alanı içerisinde yer alan Malatya evlerinin sokak cepheleri ve yerleşim plan bilgileri yer almaktadır.

Tablo 1. Yerleşim Özellikleri-Malatya Merkez (Durgun, 2006: 90-145'den geliştirilmiştir.)

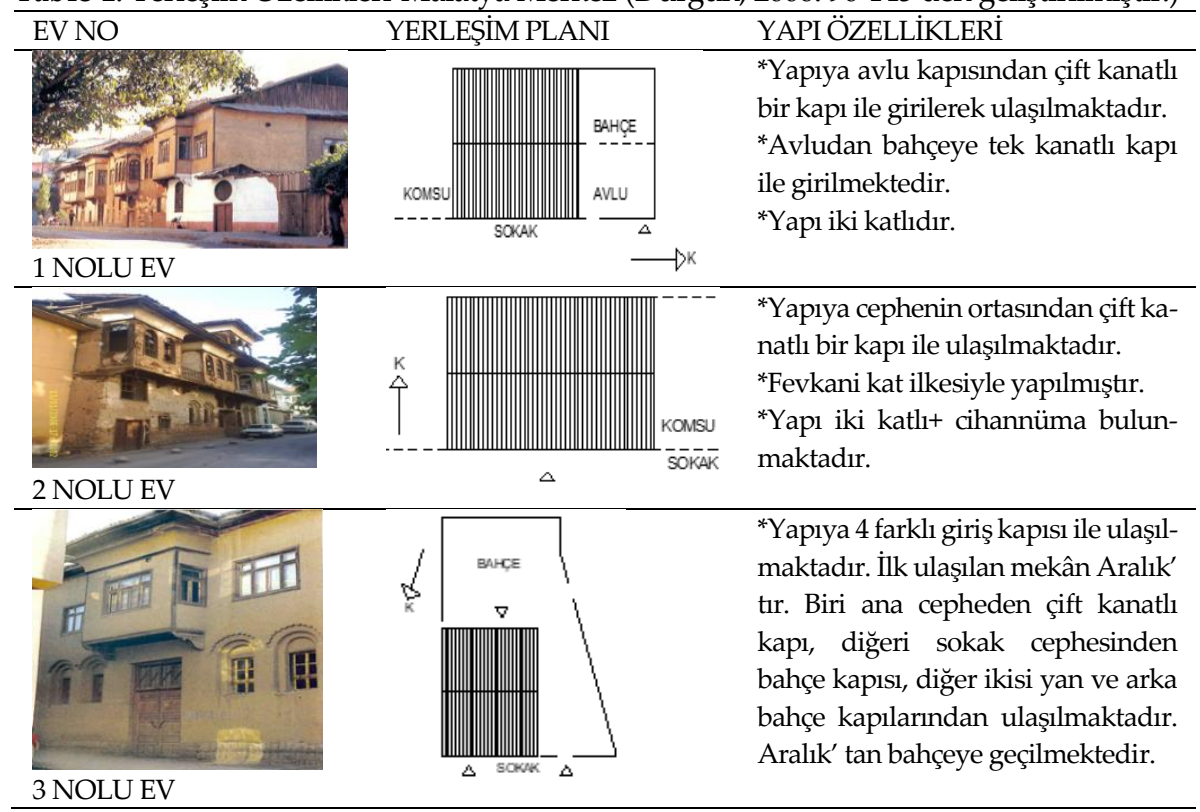




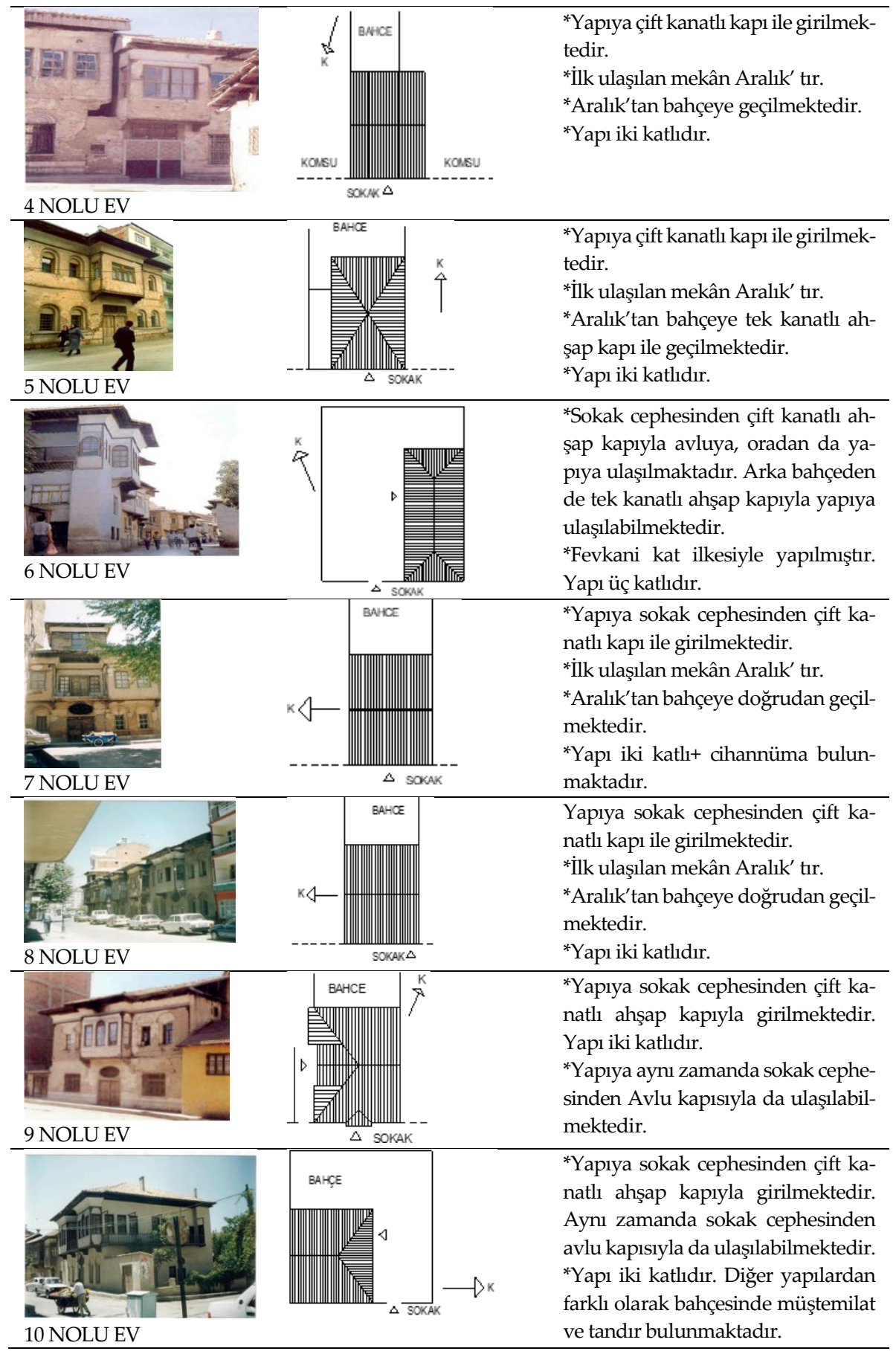




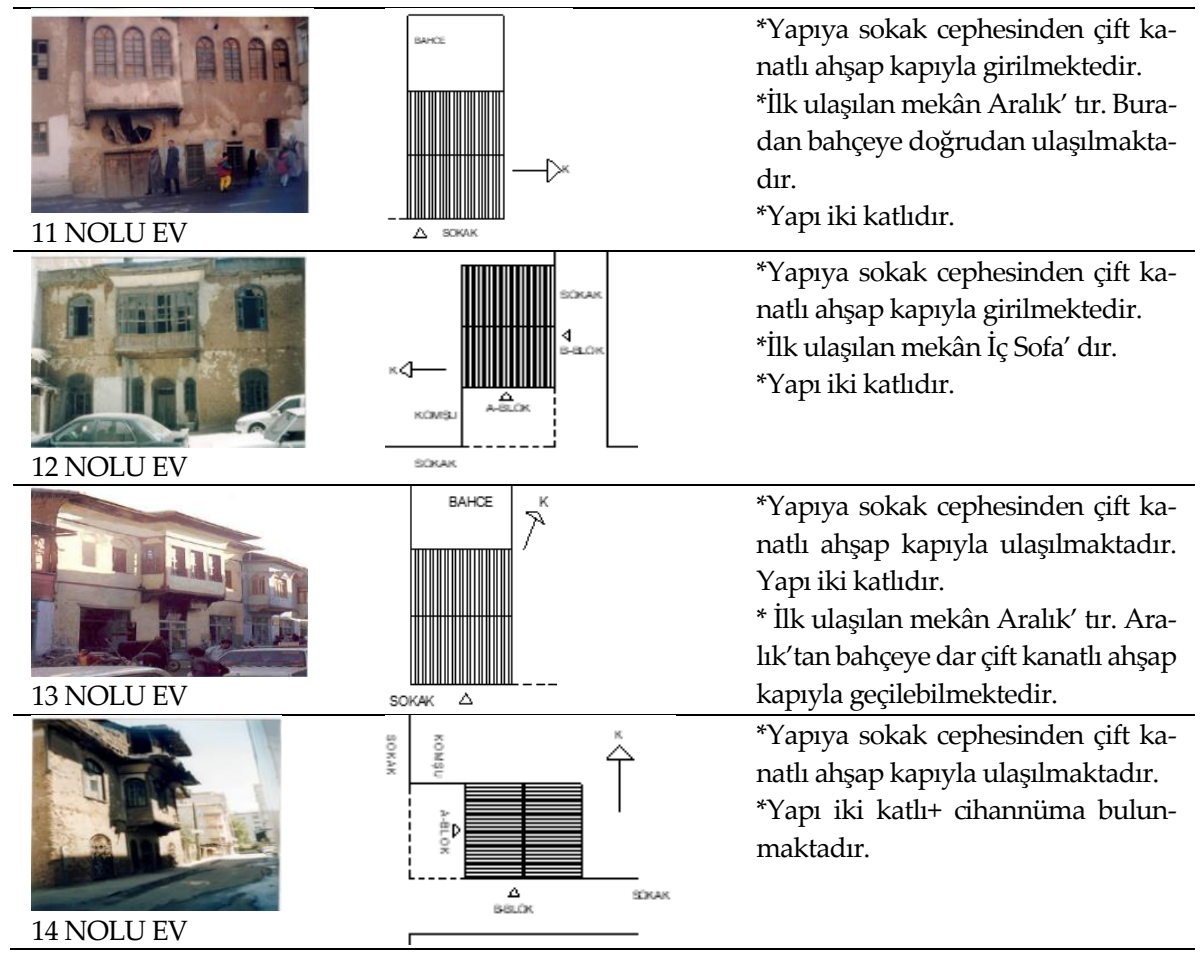

Tablo 2'de çalışma alanı içerisinde yer alan Eski Malatya evlerinin sokak cepheleri ve yerleşim plan bilgileri yer almaktadır.

Tablo 2. Yerleşim Özellikleri-Eski Malatya (Fotoğraflar: Baran, Aykal ve Kocaman. 2018)

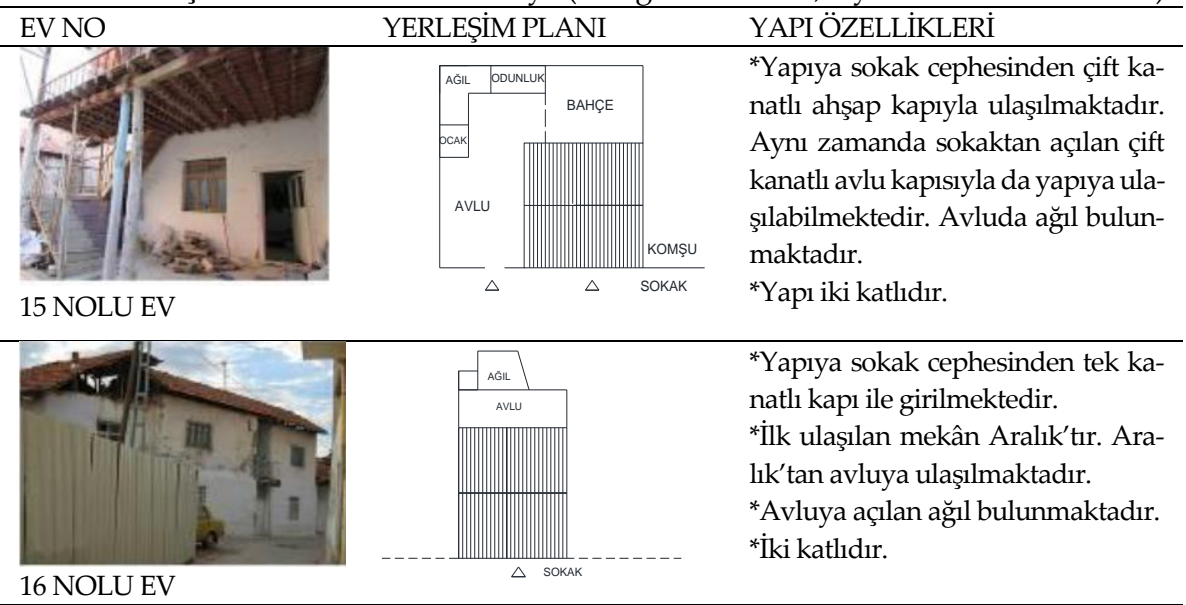




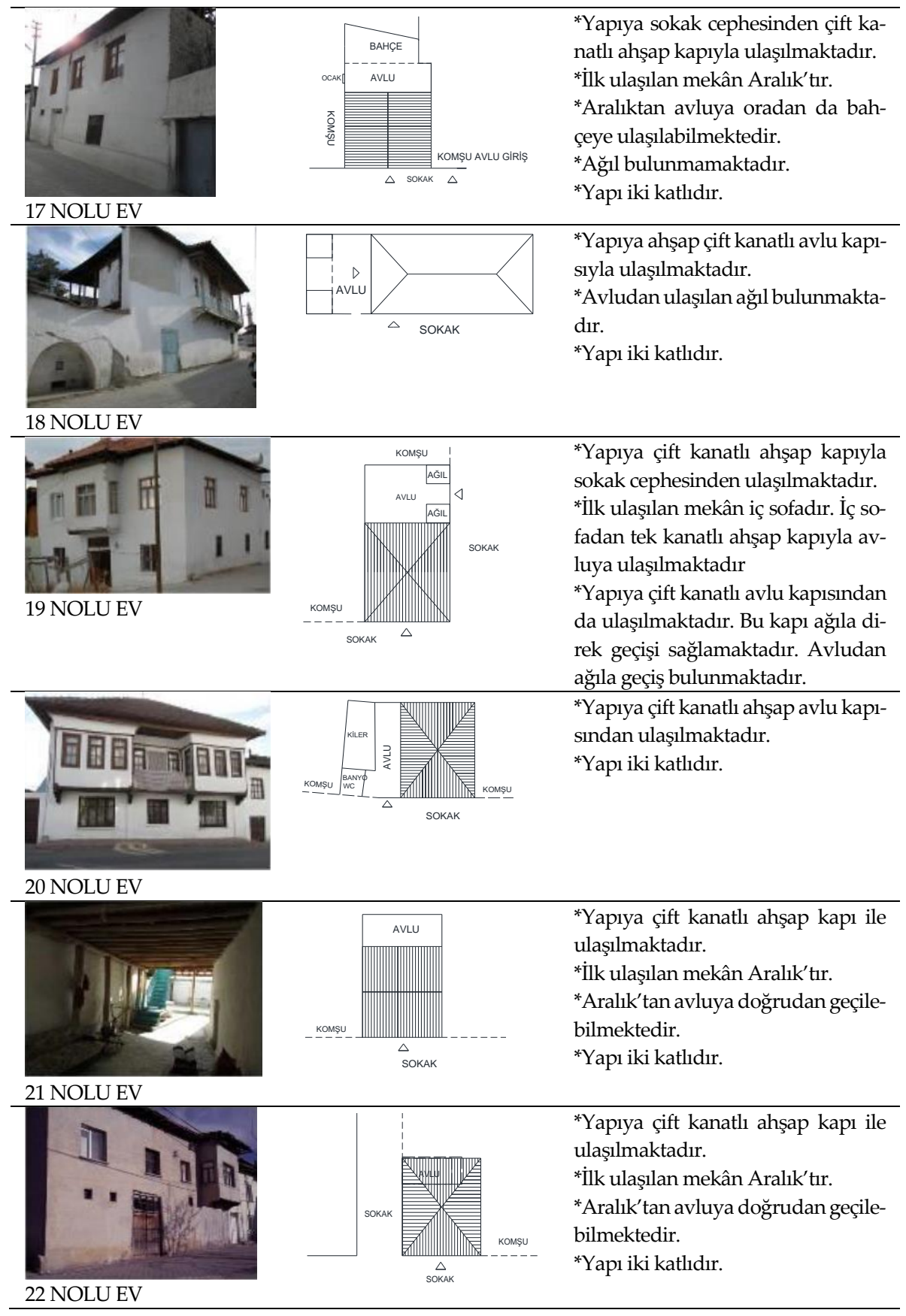




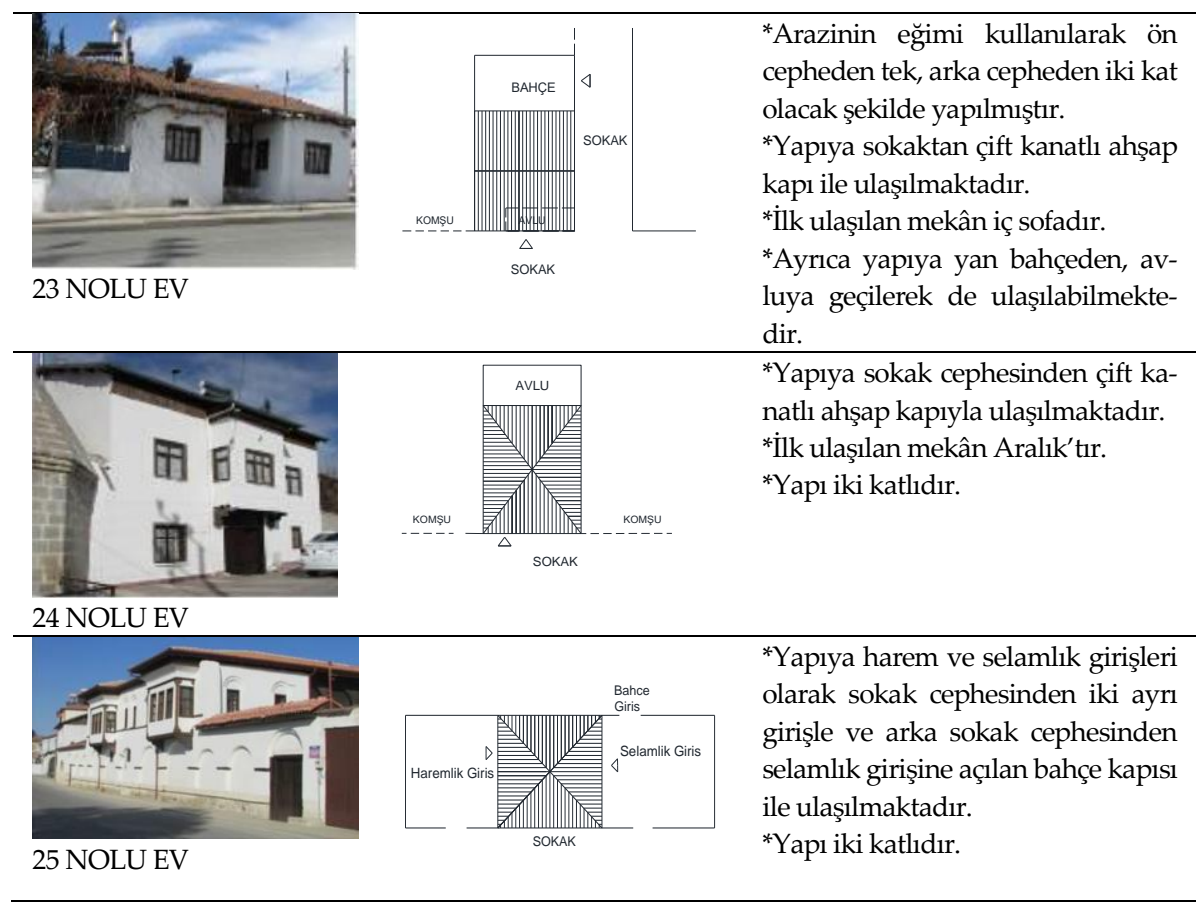

\section{Geleneksel Malatya ve Eski Malatya Evleri Yerleşim Dokusu}

Çalışma alanı içerisinde yer alan geleneksel evlerin kentsel doku içerisinde hangi evrelerde yer aldığını anlayabilmemiz için kentsel dokunun değişimindeki evrelere kısaca değinmemiz gerekmektedir. Bu evreler dört bölümden oluşmaktadır.

- Birinci evre

- İkinci evre

- Üçüncü evre

- Dördüncü evre' dir.

\section{Birinci evre-bahçe içinde ayrık düzen yapılaşma}

En eski sokak düzeninde alabildiğine geniş arazi parçalarına genellikle ön bahçesiz ayrık düzende birer konut gelerek oluşan bir yerleşim düzeni söz konusudur. Bu doku, daha çok kent yerleşmelerinin bile tamamen tarımsal karakterini yitirmediği dönemlerin ürünüdür (Eruzun ve Sözen, 1992, s.19). Bu doku örneği Eski Malatya evlerinde görülmektedir (Şekil 3). 


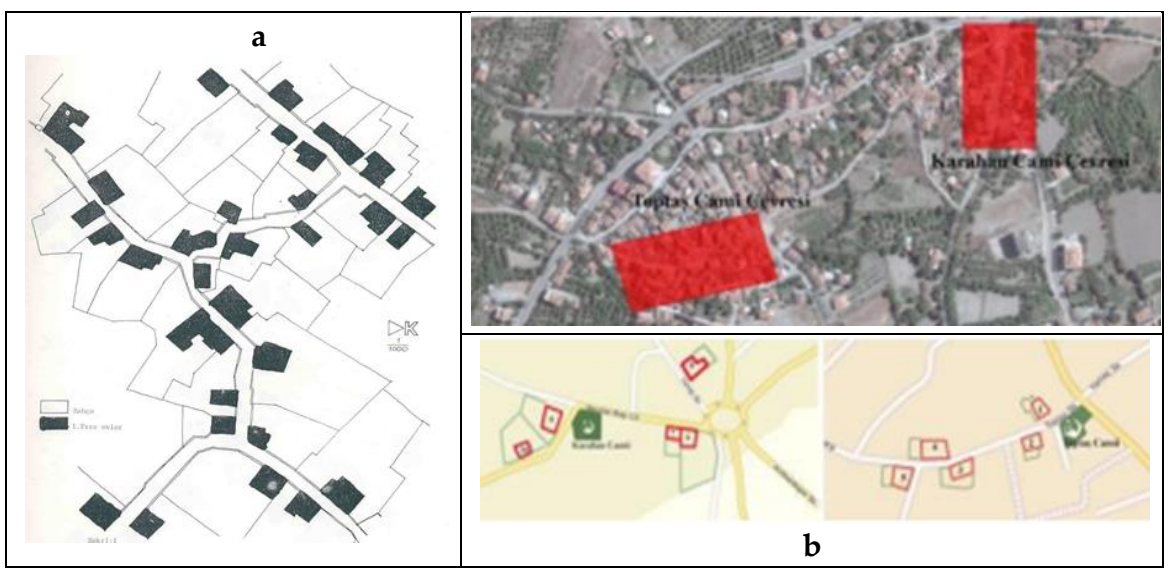

Şekil 3.a Birinci evre yerleşim doku örneği (Eruzun ve Sözen, 1992: 19).

b. Eski Malatya(Topbaş ve Karahan Cami Çevresi) birinci evre yerleşim doku örneği (Baran, Aykal ve Kocaman, 2018:1312)

\section{2. İkinci evre-bahçe içinde ikili ve üçlï bitişik düzen yapılaşma}

Aileden kopan ve ayrı ev açan çocukların yan bahçelere yeni ev yapmaları, araziyi bölmeleri, sokak düzeninde yoğunlaşma getirirken, bahçelerin de küçülmelerine neden olmuştur. Böylece yer yer ikili ve üçlü bitişik gruplaşmalar ortaya çıkmıştır (Eruzun ve Sözen, 1992, s.19). Bu doku örneği Şekil 4' de gösterilmektedir.
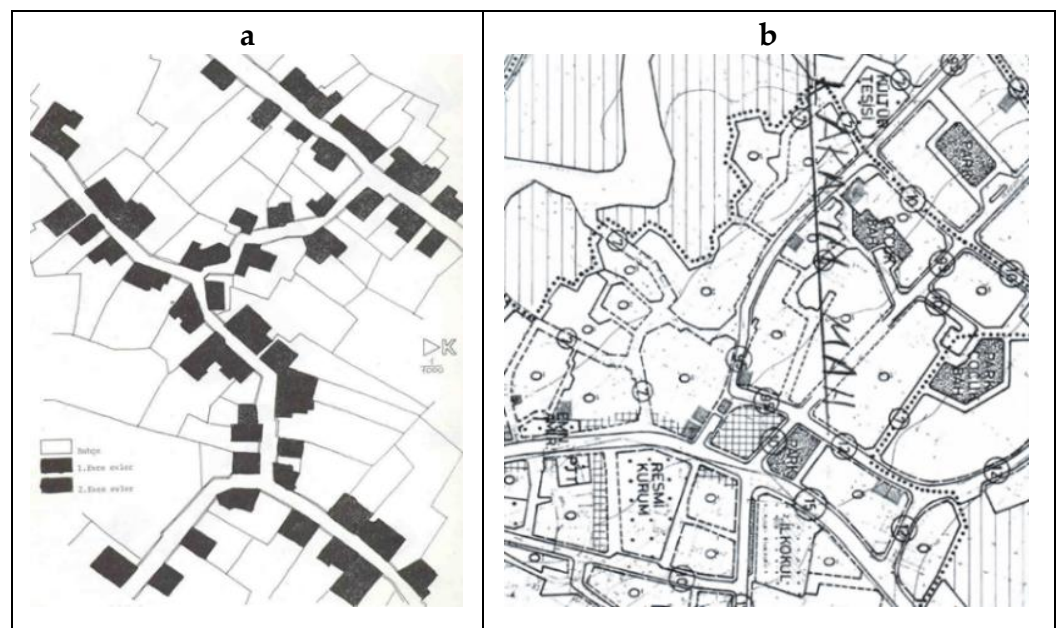

Şekil 4.a. İkinci evre yerleşim doku örneği (Eruzun ve Sözen,1992, s.19).

b. Malatya Molla Kasım mahallesi ikinci evre yerleşim doku örneği (Malatya Belediye Arşivi) 


\section{3. Üçüncü evre-üç katı geçmeyen bitişik düzen yapılaşma}

Artık yan bahçelerin hemen hemen tümünün yapılaşmaya açılması ile bitişik düzendeki sokak dokularının yaygınlaşmasıdır. Bu dönemde nüfus artmaya başlamış, arka bahçe içinden yollar geçilerek arsalar daha da küçülmüş, hatta iki katlı olan evlereüçüncü kat ilaveleri gelmeye başlamıştır (Eruzun ve Sözen, 1992: 19). Bu doku örneği Şekil 5’ de gösterilmektedir.

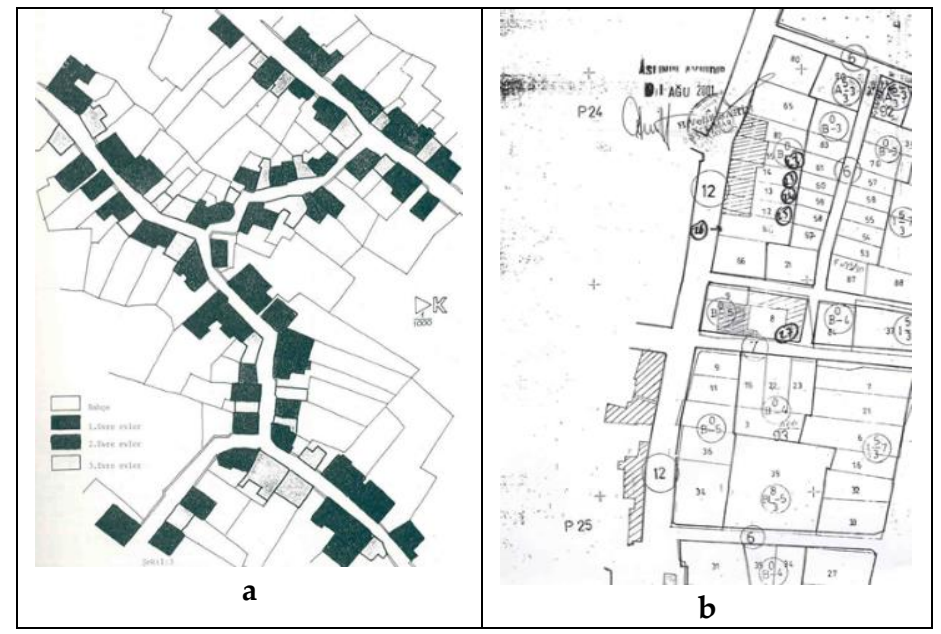

Şekil 5.a. Üçüncü evre yerleşim doku örneği (Eruzun ve Sözen, 1992, s.19). b. Malatya merkez Sinema caddesi geleneksel konut doku örneği (Durgun, 2006, s.63)

\section{Dördüncü evre}

Yerleşik kent alanlarında imar yönetmeliği uygulamaları Cumhuriyet Dönemi'nin 1950'li yıllardan sonra yaygınlaşan yönetmelik hükümlerine göre biçimlenen bitişik düzen yüksek yapılaşmasıdır. Bu dönemde sokaklar ve caddeler korunmuş olmakla birlikte insan ölçeğindeki eski yollar araç yolu olarak kullanıma açılmaya başlanmasıyla geleneksel kent dokusu oldukça bozulmaya uğramıştır (Eruzun ve Sözen, 1992, s.19). Malatya sivil mimari yapıları arasında dördüncü evre özelliği gösteren yapı grubu olarak Malatya Sinema caddesi günümüz kullanımı örnek teşkil etmektedir. Sivil mimari örnekleri ile yeni yapılaşma birlikte kullanılmaktadır. 5 nolu bitişik nizam konak grubu geleneksel evin sol ve sağ komşuluğunda dört katlı betonarme yapı bulunmaktadır. 3 nolu konak komşuluğunda, aynı şekilde 4 katlı betonarme yapı inşa edilmiştir (Şekil 6). 


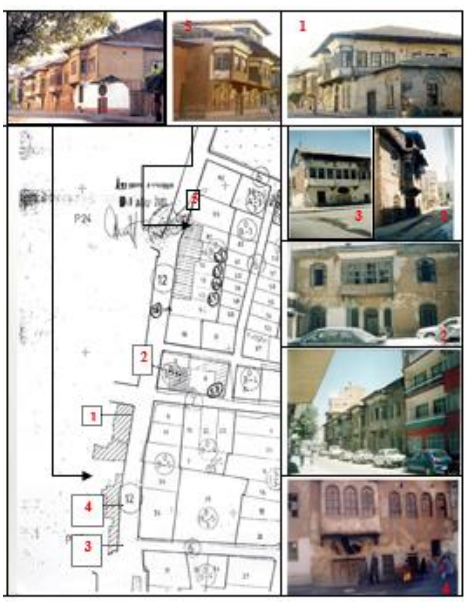

a

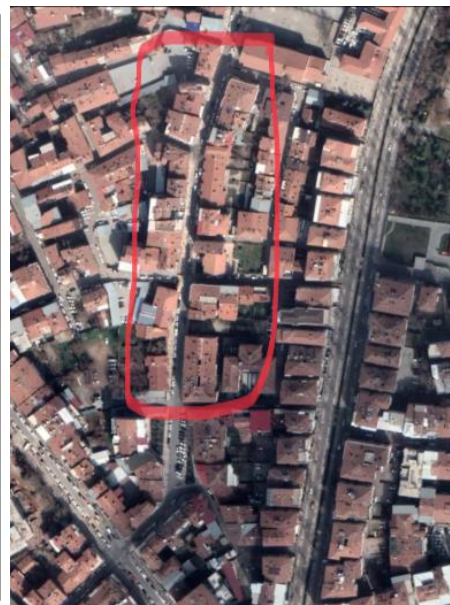

b

Şekil 6. a. Malatya merkez Sinema caddesi geleneksel konut kullanımı b. Sinema caddesi güncel hava fotoğrafı(Geleneksel ve güncel çok katlı konut kullanımı)

Bu evreler incelendiğinde;

Çalışma alanı içerisinde yer alan Malatya evlerinin çoğunun üçüncü evre özellikleri gösterdiği, birkaç erken dönem örneklerin ise, ikinci evre özellikleri gösterdikleri görülmektedir. Eski Malatya evlerinin çoğunun ikinci evre, birkaç erken örneğin ise birinci evre özellik gösterdikleri görülmektedir.

Evler birbirlerinin manzarasını kesmeyecek şekilde sokağa dönük olarak araziye yerleşmektedir. İklim verilerinin yönlenmeye etkisi manzara yönüne göre ikinci derecede önemlidir. Yönlenmede ilke olarak sokak cephesi esas alınmıştır. Genellikle arka ve yan bahçeler, zengin ağaçlı ve yeşil görünüme sahiptirler.

Sokaklar, bitişik düzende evlerin ya da bahçelerin yan yana gelişi ile biçimlenmektedir. Sokaklar geleneksel yaşamın birer parçası olma özelliği taşımaktadır.

Beş konaklar mahallesinin içerisinde yer aldığı yerleşim dokusu, kentsel dokunun değişiminde üçüncü evreye girmektedir. Fakat incelenen örnekler arasında bazı örnekler ikinci evre özellikleri taşımaktadır.

Yan bahçelerin hemen hemen tümünün yapılaşmaya açılması ile bitişik düzende sokak dokuları yaygınlaşmıştır. Bu dönemde nüfusun artmasıyla birlikte bahçe içerisinden yollar geçirilerek arsalar daha da küçülmüş hatta iki katlı olan evlere üçüncü kat ilaveleri eklenmeye başlanmıştır. Üçüncü evrenin bu özelliklerinin yanında Malatya kent dokusu içerisinde Beş konaklar mahallesi dışında kalan yapıların bazıları da kent dokusunun oluşumunda 
ikinci evreyi yansıtmaktadır. Bahçe içerisinde ikili ve üçlü gruplaşmalar oluşmuştur. Evlenerek aileden kopan ve ayrı ev açılan çocuklar, yan bahçelere yeni ev yapmaları ile arazi bölünmüş ve sokak düzeninde yoğunlaşmalar oluşmuştur. Mücelli caddesi ve Halep caddesinde yer almakta olan konutların oluşturduğu yerleşim dokusu da üçüncü evreyi yansıtmaktadır.

Eski Malatya evlerinin ise çoğunlukla ikinci evre yerleşimlere örnek oluşturduğu görülmüştür. Bazı erken dönem örneklerinde ise birinci dönem özelliği taşıyan evlerin varlığı bilinmektedir. Bu bölgede, nüfus artışı, sanayileşme gibi yerleşim yoğunluğunu artırıcı faktörlerin az olması, yapıların bahçe içerisindeki gelişimlerini devam ettirmelerinde öncü olmuştur.

\section{Geleneksel Eski Malatya ve Malatya Evleri Yerleşim Plan Analizleri}

Geleneksel Eski Malatya ve Malatya evleri yerleşim plan özellikleri yönünden bahçeli ve bahçesiz olmak üzere ikiye, bahçeli ve bahçesiz konutlar da kendi içlerinde avlulu ve avlusuz olmak üzere farklı iki alt gruba ayrılmıştır. İncelenen 25 adet ev örneğinden 17'si bahçeli, 8'i bahçesizdir. Şekil 7'de evlerin yerleşim planlarında yer alan yapı-açık alan ilişkileri gösterilmiştir.

\section{Yapı-açık alan ilişkisi}

Parsel sınırları içerisinde yer alan yapıların yerleşimleri incelendiğinde bitişik düzen ve ayrık düzen olarak ikiye farklı şekilde konumlandıkları görülmüştür. Parsel içerisinde yapının konumu ve bahçe/avlu kullanımının varlığı değerlendirilmiştir. Aşağıda şekil 7'de geleneksel Eski Malatya ve Malatya evlerinden hangilerinin bu yapı grupları arasında yer aldığını göstermektedir. Malatya evlerinden $10^{\prime}$ u bitişik düzende 4 'ü ayrık düzende yerleşim özelliği göstermektedir. Bu yapılar arasından da 4'ü bahçeli 3'ü bahçesiz olarak yer almaktadır. Ayrık düzende yapılmış tüm yapıların bahçesi bulunmakta, bitişik düzende bahçesiz olan iki yapıda avlu da bulunmamaktadır. Bitişik düzende bahçeli olan 9 yapıda da aynı zamanda avlu mevcuttur.

Eski Malatya evlerinden 3'ü bitişik düzende ve bahçesiz, 8 tanesi ayrık düzende yerleşim özelliği göstermiştir. Bu 8 ayrık düzen yapıdan 4 'ü bahçeli, 4'ü bahçesiz olarak yapılmıştır. Bahçesi bulunmayan 4 konut da ise avlu kullanımının yaygin olduğu görülmüştür.

Malatya evlerinde hayvan barınması için ağıl bulunmazken, Eski Malatya evleri bahçesinde ağıl kullanımının yaygın olduğu görülmüştür. 
Eski Malatya evlerinde ağıl komşuluğunda çeşme öğesinin varlığı, hayvanların su içmesinde ve geniş bahçe alanının sulanmasında kullanılmış olacağını düşündürmüştür. Malatya evlerinde ise çeşme kullanımının varlığına rastlanmamıştır.

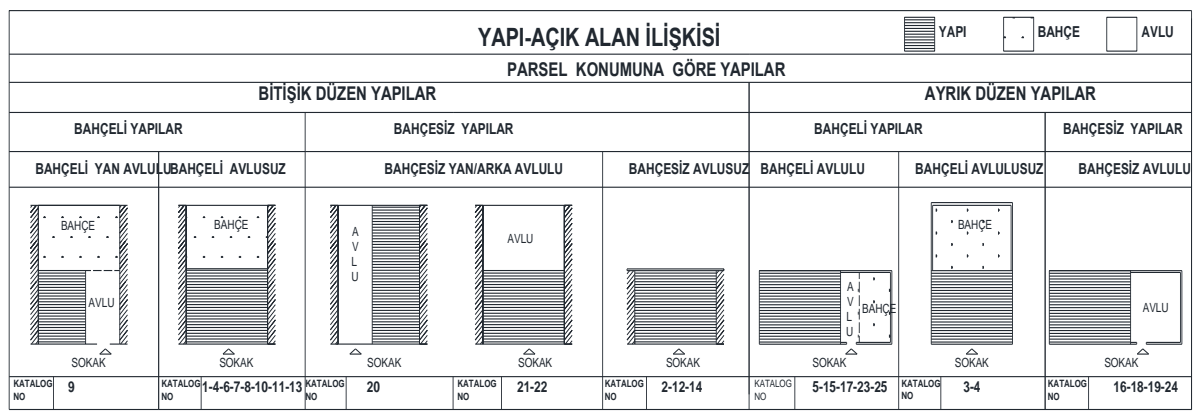

Şekil 7. Yapı-açık alan ilişkisi

\section{Yapt-giriş ilişkisi}

İncelenen konutlar arasında sokaktan doğrudan yapıya girilen örnekler ile bahçeden ya da avludan yapıya girilen örnekler bulunmaktadır. Sokaktan öncelikle bahçeye veya avluya, oradan da yapıya giriliyorsa, bu tip konutlarda bahçe ile sokak arasındaki bağlantı, cümle kapısı ile kurulmaktadır (Kuban, 1982, s.226-227). Aşağıdaki şekil 8' de evlerin yapı-sokak- giriş ilişkileri gösterilmektedir.

Malatya evlerinden 11'i tek girişli, 3 tanesi çift girişlidir. Tek girişli evlerden 9'una doğrudan ulaşılabilmekte, 2'sine bahçe kapısından girilerek dolaylı olarak ulaşılabilmektedir. Çift girişli yapılardan, yapıya doğrudan ulaşım dışında, 2'sine bahçeden dolaylı olarak, 1'ine de avludan dolaylı olarak ulaşılabilmektedir.

Eski Malatya evlerinden ise, 6's tek girişli 4'ü çift, 1'i ise üç giriş özelliğindedir. 5 tek giriş özelliğindeki yapıya sokak cephesinden doğrudan ulaşılmakta, 1'ine avlu girişinden dolaylı olarak ulaşılabilmektedir. Çift girişi bulunan 4 yapının 2'sine avludan, 2'sine bahçeden dolaylı olarak giriş sağlanmaktadır. Üç girişi bulunan 1 yapıya dolaylı olarak bahçeden geçişler bulunmaktadır. Bu yapıda üç giriş bulunması erken dönem özelliği taşımasından kaynaklanmaktadır. Güvenlik sorununun az olduğu ve harem/selam ayır1mının belirgin olduğu yapı grubu olmasından dolayı, yapıya giriş farklı kapılardan sağlanmıştır. 


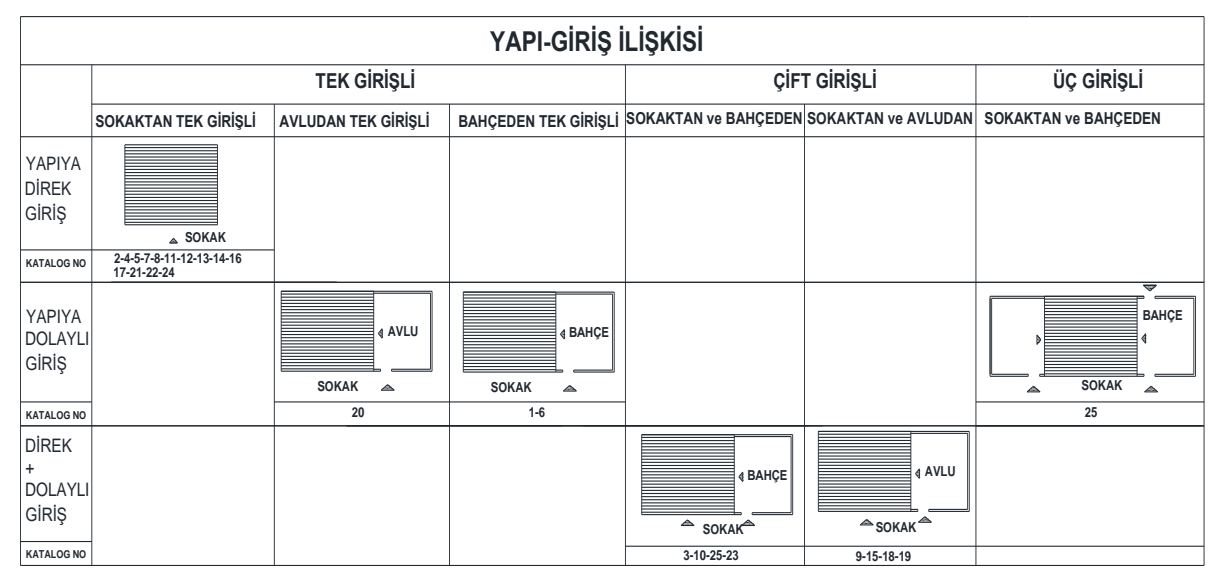

Şekil 8. Yapı-giriş ilişkisi

\section{Tartışma ve Sonuç}

Göç, insanlığın yaşadığı, tarih boyunca var olan, toplumsal bir gerçekliktir. Bireyin ya da topluluğun sadece yer değiştirmesi olarak tanımlanamaz. Malatya kentinin yer değiştirme öncesinde var olan kültürel davranışın, yani yarı göçebe yaşam biçiminin şekillendiği tarım arazileri üzerinde, günümüz Malatya kenti yeniden doğmuş ve gelişimini günümüze kadar devam ettirmiştir. Mevsimlik yayla kültüründen (yarı göçebe yaşam biçimi) yerleşik hayata zorunlu geçişin yaşanmış olduğu Malatya kentinde, geleneksel evler ve yerleşim özelikleri de bu süreçten etkilenmiş ve biçim değiştirmiştir. Zorunlu göç ile yerleşim alanındaki nüfusun artması, altyapının yetersiz kalması ve evlerin kış şartlarına göre yapılmamış olması Malatya'da önemli kentsel sorunları beraberinde getirmiştir. Bu sorunların çözümü için çeşitli yasal düzenlemelere gidilmiştir. Bu düzenlemelerle ve yeni yaşam şeklinin oluşumu ile şekillenen geleneksel evlerin yerleşim özelliklerinde de tipolojik farklılıklar tespit edilmiştir. Yapılı çevredeki tipolojik veri farklılıklarının, farklı yapım dönemlerinden, dönemin yapım ilkelerindeki farklılıklardan, kentin il olması ile değişen yeni yasal düzenlemelerden ve değişen yaşam biçiminden kaynaklanmış olduğu sonucuna varılmıştır.

Bu anlamda, sürdürülen mevsimlik göç biçiminin kalıcı hale gelmesinde, bürokratik karar vericilerin etkin olduğu görülmüştür. Askeri güvenlik önlemi olarak alınmış olan bu bürokratik karar, halkın zorunlu olarak mevsimlik geçici yaşam alanlarına göç etmeleri ile sonuçlanmıştır. Mevsimlik yaşam alanı iken kalıcı yerleşim alanına dönüşen kentte, bölgedeki sınırlar yeniden 
düzenlenerek, bağlık kırsal arazi sınırları, kentsel konut sınırlarına dönüşerek parsel sınırları küçülmüş, evler bitişik nizam düzeninde yapılmaya başlanmıs, bahçe sınırları azalarak avlu kullanımında artış olduğu belirlenmiştir.

Eski Malatya evlerinin tamamı iki katlı, Malatya evlerinde ise yapım evre ve dönem farklılıklarından dolayı üçüncü katın eklenmeye başladığı görülmüştür.

Eski Malatya'da hayvancılıkla uğraşan halk, tarım yapmak için yılın yaklaşık yarısını Malatya'ya mevsimlik göç yaparak geçirmiştir. Ancak stratejik ülke yönetim kararı ile zorunlu göç yaşayan bu halkın kalıcı olarak Malatya'ya yerleşmesi ile burada tarım yapma alışkanlığını devam ettirmiştir. Halkın, yeni yaşam alanında eski geçim kaynakları olan hayvancılıktan vazgeçmiş oldukları, yapı-açık alan kullanımındaki ağıl öğesinin olmamasından anlaşılmıştır. Zorunlu göç ile oluşan yer değiştirmede, geçim kaynaklarının değişmiş olması, sosyo-ekonomik temelleri değiştirmiş ve farklı yerleşim özelliğinde mimari yapı ve yapı gruplarının oluşmuş olduğu görülmüştür.

Zorunlu göçe tanıklık eden Eski Malatya ve Malatya'nun geçmişinde bulunan özgün izleri, ancak o kentin bizlere bıraktıkları somut mimari ve kentsel okumalarla ortaya çıkarabilmekteyiz. Çalışmada ortaya konan tipolojik yerleşim çalışması, kentin özünde var olanı kavramaya ve onun sahip olduklarını sürdürmeye yöneliktir. Bu çalışma ile geleneksel evleri yakın çevresi ile değerlendirerek, kent ile olan ara bağlantısının kenti şekillendirmedeki önemine vurgu yapılmak istenmiştir. Bu kapsamda yapılmış olan tipoloji çalışması ile kente ait olan parçaların bütünü oluşturduğu ve bütünden ayrılamayacağı gösterilmiştir. 


\title{
Extended Abstract
}

\section{The tradition of establishing a space that started with seasonal migration from Old Malatya to Malatya turned into permanent settlement with forced migration: A review on the characteristics of civil architectural settlements}

\author{
Yelda Durgun Şahin \\ ORCID: 0000-0001-6708-9247
}

Traditional buildings are disappearing as a result of the changes that happen because of various environmental impact, managerial decision, lifestyle etc. The traditional settlement texture, which acts as a bridge between these structures, which are lost one by one, is damaged. For this reason, this interconnection, which has a great influence on the formation of traditional texture, should be examined, settlement features should be determined and recorded. With this study, it was aimed to emphasize the importance of interconnection with the city in shaping the city by evaluating the traditional houses with its immediate surroundings. In this study formed in this direction, it has been shown that the parts belonging to the city constitute the whole and cannot be separated from the whole.

As Tekeli explains, "There are reasons that keep changing and transforming in the urban space constantly on the agenda" (Tekeli 2011b:272). In this context, it is important to question the change and transformation in society's practice of establishing space, which is the factor in shaping the city. In this respect this study focused on analyzes of the residential properties, formation, the dynamics of change and transformation of Malatya, which is, located in the Eastern Anatolia region of Turkey and important Hittite city in the past. While making this examination, the concept of typology of the elements that make up the settlement texture was used.

Malatya province is located within the boundaries of Eastern Anatolia geographic region. The city has had a strategic importance in history due to the 
intersection of the commercial roads coming from Central Asia, the Middle East and Mesopotamia and its position in a connection that connects to the west. The city of Malatya was reconstructed and shaped on the outskirts of Beydağları, in an oval area after two relocations. The first of this change occurred from Arslantepe, located in the town of Bahçebaşı in the district of Eski Malatya (Battalgazi), to the district of Eski Malatya (Battalgazi), and the second to Malatya (Aspuzu) in today's residential area of Old Malatya. The scope of this study is limited with the migration from old Malatya to Malatya, the second relocation of the city. In this context, a comparative study has been made between the old Malatya civil architecture samples and Malatya civil architecture samples layout plans.

It is known that the Ottoman army was placed in the houses in Old Malatya in line with the military security decision taken by the order of II. Mahmut in 1838. The people who had to evacuate their houses had to move to highland houses (Aspuzu vineyards / modern Malatya settlement). In this study, land uses, settlement orders, structure-open space relationships, building entrance relationships, examples of civil architecture in Old Malatya and Malatya (the new settlement area used by the people in the highlands in the summer) are addressed. While evaluating these relations, 11 Old Malatya and 14 Malatya civil architecture samples were chosen as the sample area. Spatial comparisons were made between the old Malatya, which is the living area of the people of Malatya before being exposed to forced migration, and the new residential area of Malatya houses, and the meaning of the change was evaluated. Thus, this interconnection between our traditional houses reflecting our past lives and the scale of the city has been provided to document the architectural settlement features.

Due to forced migration, the increase in the population in the new settlement area, the inadequate infrastructure and the fact that the houses were not built according to the winter conditions brought along important urban problems in Malatya. Various legal arrangements have been made for the solution of these problems. In line with these legal regulations, a masonry building system has been used instead of wooden building construction.

The people engaged in animal husbandry in Old Malatya spent about half of the year doing seasonal migration to Malatya for agriculture. However, with the strategic country management decision, these people, who experienced forced migration, settled in Malatya permanently and continued their agriculture habits. It is understood that the people have abandoned animal husbandry, which are the old livelihoods in the new living area, without the use 
of folders in the structure-open area. In the displacement caused by forced migration, the livelihoods have changed, the socio-economic foundations have changed, and it has been observed that architectural structures and groups of structures have been formed with different settlement characteristics. It is observed that the old Malatya houses have two floors, and the third floor has started to be added in Malatya houses due to the construction phase and period differences. In the city, which turned into a permanent residential area while it was a seasonal living area, the borders in the region were rearranged, the rural borders of the vineyards turned into urban housing borders, the parcel boundaries shrank, the houses were started to be built in the adjacent order and the boundaries of the garden decreased and it was determined that there was an increase in the use of the courtyard.

As a result, it has been seen that the difference in similarity and similarity has shaped and limited the city form. A systematic perspective has been developed with the obtained typological data on the settlement features. It was concluded that the different typological data resulted from the change in the socio-economic bases and the change in the legal regulation principles valid in different construction periods. In the displacement due to forced migration, the livelihoods have changed, the socio-economic foundations have been changed, and it has been observed that the settlement texture has been formed with different settlement characteristics. The study is also important in that it has a historical document feature that should be transferred to future generations.

\section{Kaynakça/References}

Ahunbay, Z. (2017). Tarihi çeore koruma ve restorasyon. Yem Yayınları. İstanbul.

Baran, M., Aykal, F,D ve Kocaman, M (2018). Battalgazi ve geleneksel evlerinin analizi. Elektronik Sosyal Bilimler Dergisi,17(67). ISSN:1304-0278

Durgun, Y. (2006). Geleneksel Malatya evleri üzerine bir inceleme, Yüksek Lisans Tezi, Gazi Üniversitesi Fen Bilimleri Enstitüsü, Mimarlık Anabilim Dalı, Ankara.63, 90145

Eruzun, C ve Sözen, M. (1992). Anadolu'da ev ve insan, Emlak Bankası Kültür Yayınları, İstanbul.

Göğebakan, G. (2003). Doğu Anadolu bölgesinde şehir ve bu şehrin merkez olduğu il. Malatya Dergisi, 20. 473.

Kızılkaya, N. (2018). Malatya'nın ilk şehir planı süreci 1931- 1936. 8 Aralık 2018 tarihinde http://malatyahaber.com/haber/malatyanin-ilk-sehir-plani-sureci-19311936/ sitesi adresinden alınmıştır. 
Kuban,D. (1982). Türk ev geleneği üzerine gözlemler. Yem Yayınları, İstanbul.

Lewis, B. (1993). Modern Türkiye'nin doğuşu. Türk Tarih Kurumu, Ankara.

Panerai, P. ve Castex, J. (1970). Notes sur la structure de l' espace urbain, l'architecture d'aujourd'hui, 153, 30-33.

Köksal, A.., Arel, A., Gürsel, E ve Özkan, S . (2005). Selçuk Batur için mimarlık yazıları. Ankara Mimarlar Odası Yayınları. Ankara. 30-33

Ramsay,M. (1960). Anadolu'nun tarihi coğrafyası, Milli Eğitim Basımevi, İstanbul.

Sağlam, F., Korkmaz, B., Bilgin, Z., Demirbağ, H. ve Memiş, E. (2013). Malatya kent rehberi, Malatya Valiliği Yayını, İstanbul. .

Sevgen, N. (1959). Anadolu kaleleri, Doğuş Basımevi, Ankara. 240-242.

Tekeli, İ. (2011a). Kentleşmenin tanımı ve kentleşmeye ilişkin kavramlar, kent, kentli hakları, kentleşme ve kentsel dönüşüm, İlhan Tekeli Toplu Eserleri-20, Tarih Vakfı Yurt Yayınları, İstanbul.

Tekeli, İ. (2011b). Kentleri dönüşüm mekânı olarak düşünmek, kent, kentli hakları, kentleşme ve kentsel dönüşüm, İlhan Tekeli Toplu Eserleri-20, Tarih Vakfı Yurt Yayınları, İstanbul.

Tekeli, İ. (1985a). Tanzimat'tan Cumhuriyet'e kentsel dönüşüm. Tanzimattan Cumhuriyete Türkiye Ansiklopedisi.

Tekeli, İ. (1999b). 19. Yüzyılda İstanbul metropol alanının dönüşümü, modernleşme sürecinde Osmanlı kentleri. Tarih Vakfı Yurt Yayınları, İstanbul.

Turgut, H. (1999). Geleneksel Malatya evleri, 17.Tarihi Türk Evleri Haftası, İstanbul. 1019.

Yerasimos, S. (1999). Tanzimat'ın kent reformları üzerine, modernleşme sürecinde Osmanlı kentleri. Tarih Vakfi Yurt Yayınları, İstanbul. 